\title{
HELMINTH PARASITIC INFECTIONS OF THE CENTRAL NERVOUS SYSTEM: A DIAGNOSTIC APPROACH
}

\author{
By
}

AHMAD A. OTHMAN ${ }^{1 *}$, FABRIZIO BRUSCHI ${ }^{2}$, AND AHMED A. GANNA ${ }^{3}$

Department of Medical Parasitology, Faculty of Medicine, Tanta University, Egypt ${ }^{1}$, Department of Translational Research and New Technologies in Medicine and Surgery, University of Pisa, 56126 Pisa, Italy ${ }^{2}$, Department of Neurosurgery, Faculty of

Medicine, Tanta University, Egypt ${ }^{3}$

(Correspondence*: Email:ahmed_ali44@hotmail.com)

\begin{abstract}
Helminth parasitic infections of the central nervous system (CNS) occur worldwide with high prevalence in tropical and subtropical countries. Clinical evaluation of patients is mandatory, and it is convenient to group the clinical manifestations into syndromes: for example space-occupying lesions, meningitis, and encephalitis. The history should focus on residence or travel to endemic areas, diet, activities, intercurrent medical conditions, and associated clinical clues. Direct parasitological diagnosis can be reached by cerebrospinal fluid and cerebral tissue examination either by microscopy, culture, or immunological techniques. Immunodiagnosis by detection of parasite antibodies or antigens in serum could provide indirect evidence of parasitic infections. In addition, various imaging and radiological techniques e.g., computed tomography (CT) scan and magnetic resonance imaging (MRI) complement the diagnostic work-up of CNS diseases. Finally, the helminthic CNS infections of global impact, such as schistosomiasis, neurotoxocariasis, Strongyloides infection, neurotrichinosis, neurocysticercosis, and echinococcosis will be briefly discussed as regards the principal clinical and diagnostic features.
\end{abstract}

Keywords:helminth parasitic infection, Central nervous system, Diagnosis, CSF, neuroschistosomiasis, neurocysticercosis.

\section{Introduction}

Parasitic helminth infections of the central nervous system (CNS) occur worldwide with high prevalence in tropical and subtropical countries. In addition to the general predisposing factors in these regions - poverty, illiteracy, deprivation, malnutrition- is the prevalence and persistence of insect and other vectors which thrive in humid climates and which survive throughout the seasons. Now, however, with increase, ease and speed of international travel and immigration, awareness of these affections become necessary for proper management of patients everywhere. Moreover, the sharp rise of cases of immunosuppression, nowadays, especially due to the AIDS pandemic, results in global interest in opportunistic infections including parasitic ones(Atazhanov, 2009).
To understand the impact of helminthic infections of the CNS, we consider the problem of epilepsy. Epilepsy affects less than $0.5 \%$ of population in the West (Forsgren et al, 2005), but more than $1.5 \%$ in tropical regions (Preux et al, 2002). Many casesare due to parasites: cysticercosis alone accounts for about $29.0 \%$ of the cases of epilepsy of late onset in several countries. Other parasitic infections known to cause epilepsy include schistosomiasis, paragonimiasis, sparganosis, hydatid disease, and Gnathostoma spinigerum (Atazhanov, 2009).

Many parasites could affect the CNS probably due to the immunologically privileged status of the nervous tissue. Some parasites are typically neurotropic such as Coenurus, and Angiostrongylus cantonensis, while others reach the CNS by accident such as Schistosoma and Paragonimus spp. 
Moreover, some parasites may reach the CNS via haematogenous route during their migration in the body e.g. larvae of Trichinella, Strongyloides and Toxocara (Katchanov and Nawa, 2010).

Clinical evaluation of patients: Since the CNS manifestations of parasitic infections are protean; it is more convenient to cluster the clinical features into syndromes (Paugam, 2008, Solomon et al, 2006, Hughes and Biggs, 2002). Panel (1) summarizes the main clinical syndromes with brief reference to clinical manifestations and causative parasites. Proper assessment of clinical symptoms and signs would determine the next diagnostic step, for example radiological examination (suspected mass lesion) or lumbar puncture for cerebrospinal fluid collection (meningitis).

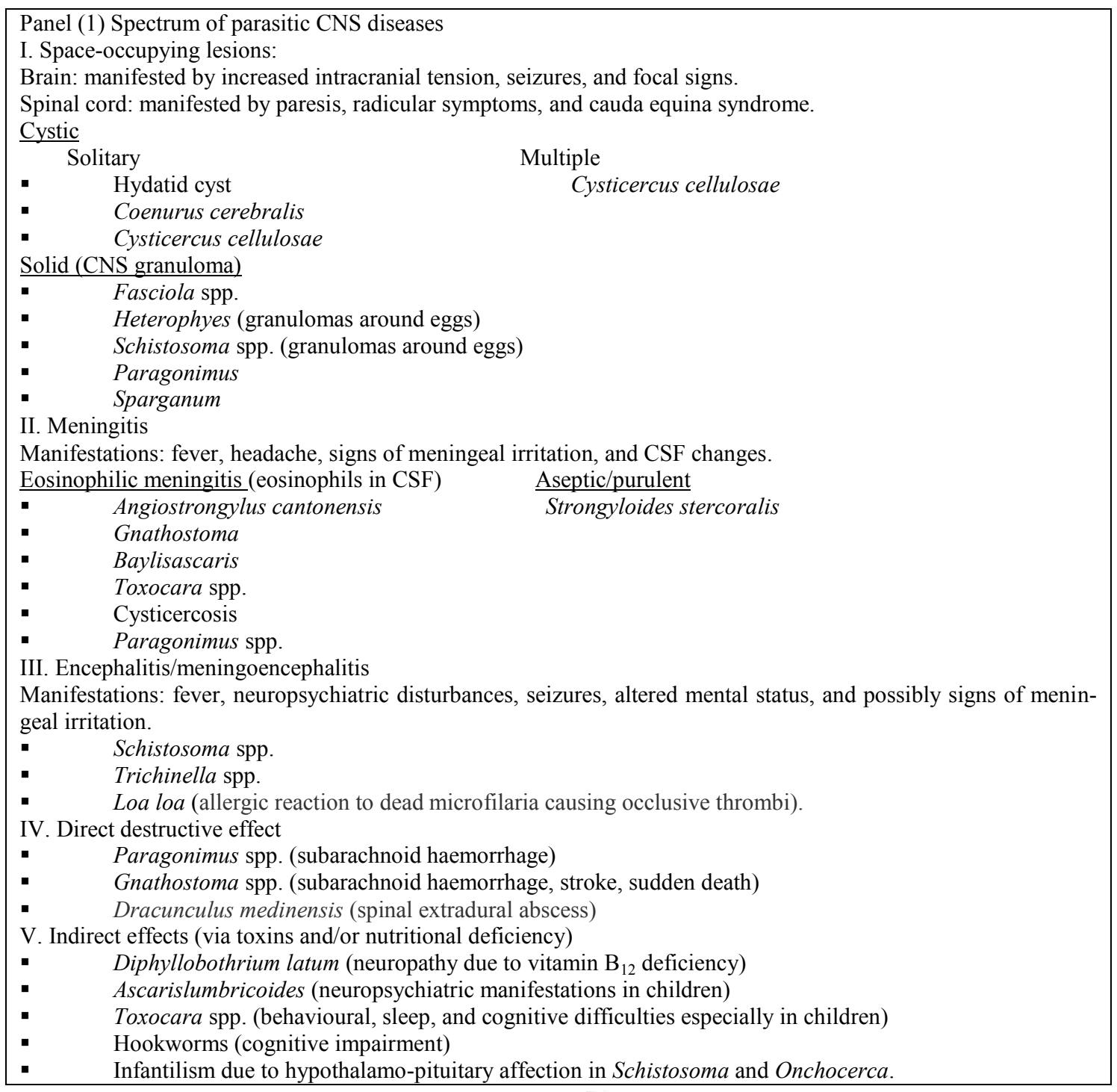

Detailed history is an essential partin the diagnostic work-up of neurological disorders with suspected parasitic etiology. The history could be obtained from the patient himself or his guardians or relatives. The following points have to be fulfilled in history (Atazhanov, 2009; Solomon et al,2006; Diagana et al, 2005; Dorny et al, 2009):
Residence or travel to endemic areas: tropical and subtropical region (Strongyloides stercoralis, Schistosoma spp.), SubSaharan Africa (Loa loa, Onchocerca volvulus), Central and South America (cysticercosis), and Southeast Asia (cysticercosis, Angiostrongylus, Paragonimus, Schistosoma japonicum). 
Diet: snails (Angiostrongylus), pork, horse or game meat (Trichinella), frogs or snakes (Sparganum, Gnathostoma), and crabs and cayfish (Paragonimus).

Activities and habits: swimming or diving in freshwater (Schistosoma spp.), contact with dogs (echinococcosis, Toxocara) or cats (Toxocara),

Intercurrent conditions: AIDS, corticosteroid therapy (Strongyloides stercoralis),

$\square$ Associated clinical features (clinical clues): subcutaneous nodules (cysticercosis, Paragonimus), periorbital oedema (Trichinella), cough and brownish sputum (Paragonimus), myalgias (Trichinella, cysticercosis), larva currens (Strongyloides).

Direct parasitological diagnosis: Cerebrospinal fluid (CSF) examination gives important data about CNS infections. The CSF should be examined microscopically as wet and stained preparations. CSF examination is invaluable for diagnosis of bacterial, viral, or protozoan CNS infections. For helminth infection, it can be useful in certain situations. For example, in eosinophilic meningi- tis (typically due to Angiostrongylus cantonensis), CSF is clear or cloudy with increased protein content. Eosinophilic pleocytosis occurs $(25-90 \%)$. It appears from $12^{\text {th }}$ day, reaching a peak after one month, and persists till 80 days post-infection, after which the pleocytosis becomes lymphocytic (Jaroonvesma, 1988).

Helminth parasites that could be detected in CSF include microfilariae of Loa loa and Onchocerca, larvae of Trichinella, Strongyloides, Toxocara, and Angiostrongylus, and eggs of Paragonimus (rare)(Paugam,2008; Garcia, 2007). Moreover, increased eosinophilic cellular content of CSF (esinophilic pleocytosis) may provide a clue for a helminthic infection of CNS. Panel (2) provides a summary of causes of CSF eosinophilia (Garcia, 2007; Wilson and Weller, 2006; Kuberski, 1979). Typically, bacterial cultures are usually needed in CNS infections to exclude a bacterial infection. In Strongyloides stercoralis disseminated infection, bacterial cultures may be positive for Gram negative organisms.

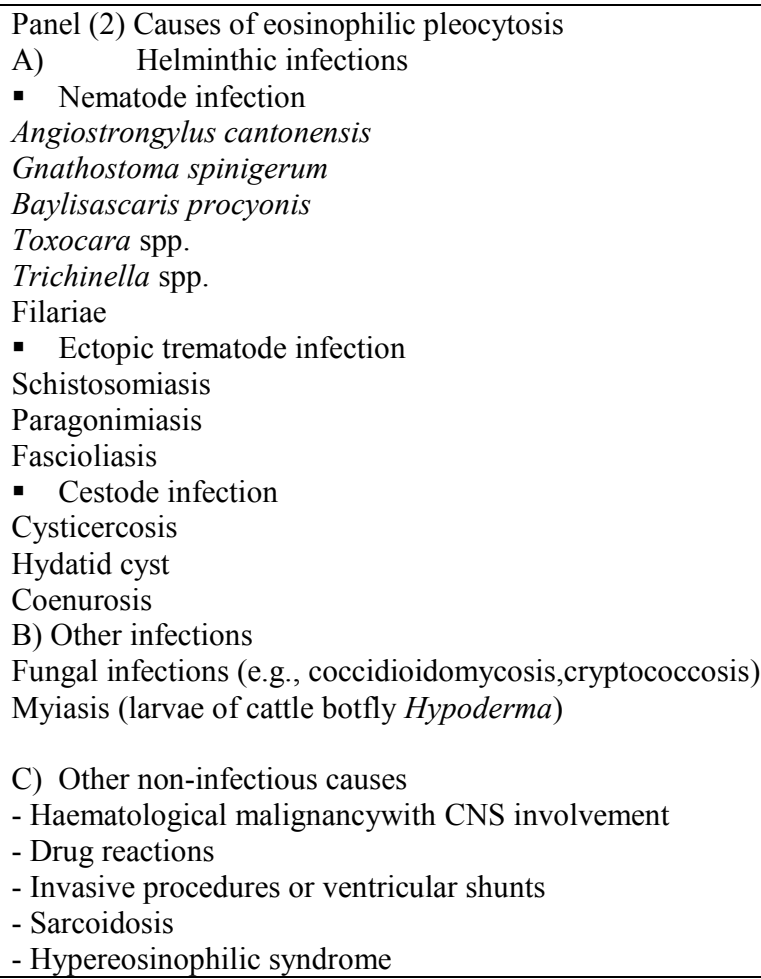

Examination of nervous tissues obtained by biopsy, after surgical removal or at auto- psy may provide definitive diagnosis. Brain biopsy specimens can be processed as touch 
or squash preparations, or as stained ones. Moreover, examination may be done by ordinay histopathological techniques which could identify tissue larval cestodes, Schistosomaspp. (egg-induced granulomas), and Paragonimus (adults and eggs are detected), or by use of immunoflurescent or immunoperoxidase staining for parasite antigens using polyclonal or monoclonal antibodies (Garcia, 2007).

Immunological and molecular diagnostic methods: Serological tests may provide the indirect evidence for parasitic etiology of CNS lesions. The required tests depend on epidemiology, clinical presentation and radiological features. These are valuable for diagnosis of cysticercosis, hydatid cysts, schistosomiasis, fascioliasis, toxocariasis, and trichinosis. The detection of antibodies has the disadvantage of inability to differentiate between current and past infections in endemic areas, but it still useful for expatriates and non-natives (e.g., travelers). Moreover, serological tests may be false positive due to cross reactions, or false negative due to low antigenic stimulus (e.g. solitary cysticercus) or immune suppression. Antigen detection, on the other hand, is useful to indicate active infection and could assess the efficacy of antiparasitic therapy. This is applicable for Schistosoma and cysticercosis (John and Petri, 2006).

Local immunological tests by finding antiparasite antibodies in CSF may be more sensitive than in serum. Evidence of in- trathecal synthesis of antibodies could confirm the parasitic etiology. These methods are described for many parasites includingSchistosoma, sparganosis, and cysticercosis (Paugam, 2008). Moreover, antigen detection in CSF has been described for neurocysticercosis (Almedia et al, 2006).

Molecular methods may ultimately offer the answer for the diagnostic inquiry especially in case of immunosuppression. These methods depend on detection of parasite nucleic acids either in serum, tissues, or CSF. The specimens could be fresh, frozen, or fixed in methanol. Unfortunately, these methods are expensive especially in tropical or subtropical milieus with limited financial and technical resources. Moreover, they are not readily available for all parasites. These techniques, however, are useful for epidemiological studies to determine the prevalence of different parasites, and for differentiation of species. Various PCR techniques were used for identification of helminth parasites to the species or genotype level (Garcia, 2007).

Other laboratory investigations:Other laboratory tests add to the diagnostic armamentarium as they may suggest or confirm the presence of parasitic infections. Further, they help to rule out other possible noninfectious causes of CNS disease. Panel (3) summarizes some of the most useful tests (Paugam, 2008; Diagana et al, 2005; Garcia, 2007).

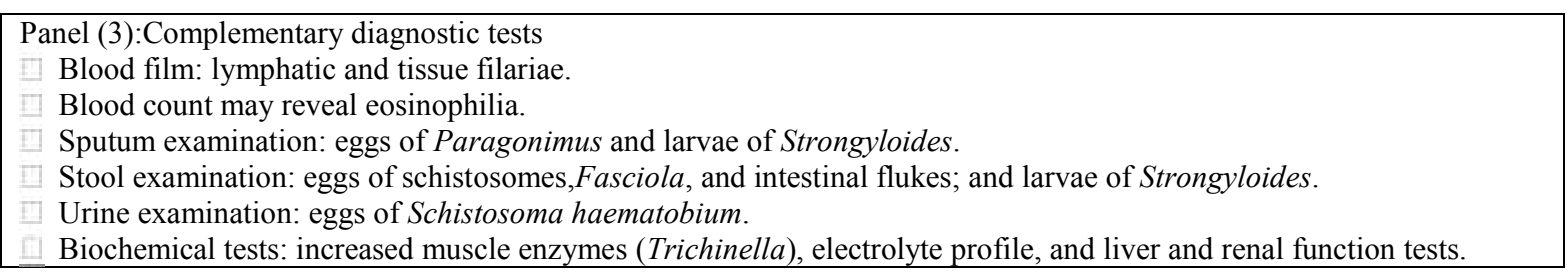

Imaging and radiological techniques: Plain x-ray may show calcifications. It can show calcified cysticerci or hydatid cyst. Characteristically, calcified Paragonimus lesions have "soap and bubble" appearance. Moreover, chest $\mathrm{x}$-ray may reveal characteristic lesions of Paragonimus or a hydatid cyst. X- rays may also show calcified subcutaneous or muscular nodules in cysticercosis. Abdominal plain radiography may show multiple fluid levels in Strongyloides stercoralis hyperinfection (John and Petri, 2006; Reeder and Palmer, 2001). 
Abdominal ultrasonography may provide evidence of hepatic granulomas of Toxocara, and complications of schistosomiasis such as periportal fibrosis and portal hypertension. Ultrasound is also a potent tool for diagnosis and evaluation of abdominal cystic and multilocular echinococcoses. Furthermore, ocular ultrasound scan may be useful for detection of ocular cysticerci (Reeder and Palmer, 2001; Lambertucci et al, 2008).

Computed tomography (CT) scan and magnetic resonance imaging (MRI) are essential component of the diagnostic work-up of CNS diseases. Today, CT and MRI are the imaging methods of choice in the evaluation of the nature and extent of cerebral infection, as well as virtually all other intracranial abnormalities. They are indispensable in space-occupying lesions as they visualize the parasitic lesion, and define its nature and extent. For example, CT and MRI scans have facilitated the diagnosis of neurocysticercosis. By CT scan, cysticerci show up as hypodense areas in which the head of the scolex can be seen. Degenerating lesions produce ring-enhancing images, whereas old inactive lesions are seen as calcified, hyperdense spots. CT scans may also show enlarged ventricles. Interestingly, heavy infection shows a "starry sky" appearance in CT (Garcia and Del Brutto, 2003; KimuraHayama et al, 2010).

Another important example is cerebral paragonimiasis which is not uncommon. The most characteristic CT or MR imaging findings are conglomerate, multiple ring-shaped, enhancing lesions with surrounding edema of variable degree. The lesions consist of aggregates of ring-like enhancing lesions, resembling "grape-clusters", representing multiple contiguous abscess-like granulomas. The classical pattern of calcification is seen as congregated multiple round nodular or cystic lesions (so-called soap-bubble or egg-shell appearance) on plain skull radiographs, CT or MR imaging, which is considered to be specific for cerebral paragonimiasis (Reeder and Palmer, 2001).
Therapeutic trial: This approach may be helpful in case of medically treatable conditions, for example toxocariasis, schistosomiasis, and cysticercosis. Amelioration of clinical features and/or improvement of radiological and imaging parameters confirm the diagnosis. However, such therapeutic testing is not always recommended due to several reasons: (a) it may involve rather long treatment schedules, (b) uses drugs (e.g., diethylcarbamazine, albendazole) that may elicit unpleasant side effects, and(c) delays the implementation of further etiological investigations if unsuccessful (Magnaval et al, 2005). Antiallergic cover in the form of corticosteroids is always advisable in conjunction with antiparasitic chemotherapy if we opt for this risky gesture of therapeutic testing.

Now, we shall go over the most peculiar clinical and diagnostic features of CNS helminth parasitic infections of global impact.

Schistosoma spp.: Schistosomiasis is one of the most prevalent parasitic diseases in the world, and is a major public health problem, particularly in tropical areas. About 200 million people are infected with Schistosoma spp. globally-120 million of them have symptoms and 20 million suffer from severe illness. Moreover, travel-related schistosomiasis has been increasingly reported (Steinmann et al, 2006; Chitsulo et al, 2000). Although uncommon in comparison to the total impact of schistosomal disease, neuroschistosomiasis is not uncommon and is propably under recognized (Solomon et al, 2006). Spinal cord schistosomiasis, especially due to Schistosoma mansoni, is considered as a primary cause of spinal cord parasitic invasion in Egypt (Badr et al, 2011).CNS disease may occur in all Schistosoma spp. during the initial stage of maturation (acute schistosomiasis) particularly in case of Schistosoma japonicum. The disease tends to be more common and severe in nonendemic exposed individuals. The affection is probably due to immunologically mediated vasculitis. In the chronic stage, the pa- 
thology is due to passage of eggs of Schistosoma to CNS where they induce spaceoccupying granulomatous reactions (Ferrari and Moreira, 2011; Ferrari et al, 2008). Schistosoma eggs (or occasionally adults) may reach the CNS via two routes: the first is through Batson's vertebral venous plexus which connects the portal venous system and inferior venae cavae to the spinal cord and cerebral veins. This route permits both anomalous migrations of adult worms in copula to sites close to the CNS followed by in situ deposition, and, occasionally, massive embolization of eggs from the portal mesenteric and pelvic venous system towards the CNS. High intra-abdominal pressure, e.g. during defecation and coughing, increases chance of retrograde flow. The second route is via arterial system either directly as in Schistosoma haematobium or through portocaval anastomotic channels after development of portal hypertension in S. mansoni (Katchanov and Nawa, 2010; Jauréguiberry et al, 2010).

In the chronic stage of infection, cerebral disease is more common in Schistosoma japonicum than in other species, and most commonly presents by seizures. On the other hand, S. mansoni and S. haematobium (to a lesser extent) affect more commonly the spinal cord leading to paresis, radicular symptoms, sphincteric problems, and cauda equina syndrome (Solomon et al, 2006). Schistosomal myelopathy has been reported to occur 38 days to 6 years after infection and is acute or subacute with rapidly progressive neurological deficit over the first 24 $\mathrm{h}$ (Scrimgeour and Gadusek, 1985). In one review of 26 patients with spinal cord disease, $11.5 \%$ died, $34.6 \%$ remained paraplegic and 54\% showed moderate to good improvement with therapy (Scrimgeour and Gadusek, 1985).

The diagnosis relies on clinical presentation, demonstration of schistosomal infection by microscopy and serological methods, imaging features, and finally exclusion of other causes of myelopathy (Lambertucci et al,
2008). CSF examination may be normal but may show increased protein and pleocytosis in the majority, but eosinophilia in only onequarter. Eggs were never found in CSF (Solomon et al, 2006). Histopathology of specimens obtained after surgical removal or biopsy provides definitive diagnosis.

In cerebral disease, CT and MRI usually show a nonspecific tumour-like lesion surrounded by oedema, associated with mass effect and heterogeneous contrast enhancement. The borders are often irregular and poorly defined. Further, MRI is very sensitive in the detection of abnormalities in patients with spinal disease, but the alterations are nonspecific. The most common findings are signal hyper-intensity on T2-weighted images, enlargement of the spinal cord (particularly lower cord and conus medullaris), thickening of the spinal roots (especially cauda equina roots), and a heterogeneous pattern of contrast enhancement on T1weighted images (Lambertucci et al, 2008; Silva et al, 2004).

Strongyloides stercoralis: Strongyloides stercoralis is a widespread intestinal nematode parasite with predominance in tropical and subtropical regions. It prevails where poverty and unhygienic habits exist. More than 50 million of humans are infected, with high rates of infection in tropical Africa, South and Central America, and Southeast Asia(Nicolas et al, 2005).Infection is contracted when infective larvae penetrate human skin and migrate to the small intestine after passing through the lungs. The parasite has a unique character among helminth parasites in that it can multiply within its hosts via autoinfection (Nicolas et al, 2005; Keiser and Nutman, 2004). Chronic strongyloidiasis is associated with gastrointestinal symptoms and recurrent respiratory and allergic features. CNS manifestations at this stage, caused by aberrant larval migration, are rare but serious, and are dominated by picture of meningitis or menigoencephalitis (Keiser and Nutman, 2004). A case of myelitis mimicking spinal cord compression with moder- 
ate CSF eosinophilia has been noted. The case suggested vascular occlusion by the larvae (Hénonet al, 1995). Also, compression of peripheral nerves par larval migration, manifested by paraesthesia of limbs and improved with antiparasitic therapy, has been reported (Peyron et al, 1985).

$S$. stercoralis is an opportunistic parasite.Thus, in patients with impaired immunity, accelerated autoinfection leads to heavy infection and/or larval dissemination in various organs. Disseminated strongyloidiasis is a term used to describe affection of tissues other than those involved in autoinfective cycle (i.e. gut and lungs) with plurivisceral dissemination of the larvae. Corticosteroid therapy is the most important single risk factor. Hyper-infection and larval dissemination occur with any steroid therapy irrespective of dosage, duration, and route of administration(Vadlamudi et al, 2006). Other risk factors include organ transplantation and immunosuppressive therapy, haematological malignancies, retroviral infections (human T-cell lymphotropic virus type 1 (HTLV-1), and HIV virus), and general debilitating conditions such as malnutrition, chronic alcoholism, cirrhosis, hypogammaglobulinaemia, and Kala-azar (Keiser and Nutman, 2004).

Spread of the larvae to CNS presents commonly with meningeal signs and symptoms. Meningitis may be aseptic or purulent. Gut bacteria gain access to the blood through the intestinal lesions or carried by migrating Strongyloides larvae in the gut or on their surface. The patient with CNS disease may present with headache, altered mental state, seizures, signs of meningeal irritation, and rarely coma (Keiser and Nutman, 2004; Scowden et al, 1978). In patients with meningitis, spinal fluid may show parameters of aseptic meningitis (i.e., lymphocytic pleocytosis, elevated protein, normal glucose, negative bacterial cultures) (Celedon et al, 1994) or demonstrate characteristics of a gram-negative bacterial infection. Cerebrospinal fluid cultures in septic menin- gitis have grown Proteus mirabilis (Liepman, 1975), Klebsiella pneumonia (Kramer et al, 1990), Escherichia coli, Enterococcus faecalis (Link and Orenstein, 1999), and Streptococcus bovis (Link and Orenstein, 1999), among others. Eosinophilic meningitis has not been observed. Moreover, filariform larvae reaching the CNS via haematogenous route would occlude small vessels resulting in microinfarcts and abscesses. The larvae may also traverse the perivascular spaces to cause granuloma formation in the meninges or parenchyma (Solomon et al, 2006).

Definitive diagnosis depends on isolation of larvae from stool, intestinal aspirate, and/or sputum, and occasionally from CSF. Serological tests may be useful especially in non-endemic people. The diagnosis requires high degree of suspicion in the context of immunosuppression in individuals who had lived or had travelled to endemic regions. Gastrointestinal and respiratory manifestations may accompany CNS involvement and give a clue for the proper diagnosis. Cutaneous lesions such as petechial hemorrhages and the pathognomonic larva currens are additional clues. Furthermore, persistent but fluctuating eosinophilia, maintained by the cycles of autoinfection, is an important biological feature in chronic infection. It may reach up to $40 \%$. However, it may be absent in disseminated disease due to immunosuppression (Nicolas et al, 2005; Keiser and Nutman, 2004).

Toxocara spp.: Toxocariasis is a soiltransmitted helminthozoonosis due to infection of humans by larvae of Toxocara canis (T. canis), or less commonly $T$. cati. Seroepidemiologic surveys showed prevalence to be $2-5 \%$ and $14-37 \%$ in urban and rural areas of Western countries respectively; while in developing countries prevalence may reach $50-80 \%$. The principal risk factors include male gender, geophagia, contact with dogs, and residence in a rural region. After ingestion of Toxocara eggs, the larvae penetrate the gut to migrate through the liver 
and other viscera with a special predilection for the central nervous system (Magnaval et al, 2001).

Neurotoxocariasis is being recently diagnosed with increasing frequency due to improved diagnostic tools. Neurological toxocariasis may present as meningoencephalitis with eosinophilic pleocytosis (Vidal et al, 2003), meningoradiculitis (Robinson et $a l, 2002)$ or transverse myelitis with eosinophils in CSF (Goffette et al, 2000). Moreover, many studies have suggested possible association between Toxocara infection and epilepsy (Arpino et al, 1990). Other possible associations include cognitive and behavioural abnormalities especially in children (Worley et al, 1984; Taylor et al, 1988). If detected and managed early, the prognosis of neurological toxocariasis is favourable (Finsterer and Auer, 2007).Interestingly, it was found that laboratory mice infected with $T$. canis were less explorative and less responsive to novelty. They also displayed reduced levels of anxiety to aversive situations(Cox and Holland, 2001).In another experiment the infected murine host revealed alterations of social behavior with little evidence for a specific and hence an adaptive alteration (Holland and Cox, 2001). However, in humans the situation is less clear. Lower academic performance was recorded in Toxocara-infected children (Worely et al, 1984). Further, Taylor et al. (1988) reported high rates of behaviour disturbances in children with raised Toxocara titres (Taylor et al, 1988).

Diagnosis of neurological toxocariasis depends mainly on serology and imaging as well as exclusion of other etiologies. In cases of meningitis, eosinophilic pleocytosis is usually present, and determination of antiToxocara IgG in CSF can help in diagnosis (Finsterer and Auer, 2007). MRI can show granulomas appearing as hyperintense areas on proton-density and T2-weighted images, primarily located cortically or subcortically. CT can also detect these lesions but to a less sensitive extent (Xinou et al, 2003). Finally, improvement of pathological changes detected by different radiological and imaging techniques after administration of anthelmintic therapy is a good evidence of toxocaral etiological association (Azum a et al, 2002).

Trichinella spp.: Nematode worms belonging to the genus Trichinella are the etiological agent of a zoonosis named trichinellosis. These parasites are widespread in wildlife on all continents but Antarctica, and in domestic pigs of many countries. Infections occur in humans where cultural food practices include dishes based on raw or undercooked meat and meat products of different animal origins (e.g. pork, horse, game). It has been estimated that as many as 11 million people are infected worldwide with Trichinella species and many others are at risk. It is now also recognized as a reemergent problem in Latin America, Eastern Europe and Asia (Dupouy-Camet and Bruschi, 2007).

Central nervous system damage is due to the presence of larvae which affect the blood capillaries with a following vasculitis and perivasculitis, the result of which is represented by diffuse or focal lesions. The migrating larvae may wander, causing tissue damage before reentering the bloodstream, or arrest in the tissue, eliciting a granulomatous reaction, rich in eosinophils, which can destroy the parasite. When activated, the eosinophils degranulate releasing molecules such as eosinophil-derived neurotoxin and major basic protein which are toxic for the neurons (Durack et al, 1979). The so-called neurotrichinosis should be suspected when a case of trichinellosis is ascertained, according to a specific algorithm, where neurological signs help in defining a suspected case of acute trichinellosis (Dupouy-Camet and Bruschi, 2007). Neurological complications may be prevented by an early treatment. When present, they include many signs and symptoms deriving from brain or eye involvement. Persons with severe disease can show consciousness disorders or excessive 
excitement and frequently somnolence and apathy; some of the persons with these symptoms show signs of meningitis or encephalopathy. Brain damage, usually occurring within a few days after the onset of fever, may result in diffuse encephalopathy or focal signs such as disorientation, memory disturbances, frontal syndrome, behavioural disturbances, transient hemiparesis or hemiplegia, oculomotor dysfunction, aphasia, and cerebellar syndrome (Ellrodt et al, 1987; Ryczak et al, 1987; Fourestiéet al, 1993; Nawhorter and Kazura, 1993).

At the CT scan or magnetic resonance (MRI), small hypodensities are visible (Feydy et al, 1996; De Graef et al, 2000; Gelal et al, 2005). CT scan can show nodular multifocal hypodensities, sometimes bilateral and localized at cortical level or under-cortical topography or within the hemispherical white substance. After injection of contrast medium, enhancement is present in cortical lesions (on an ischaemic basis) and, much more rarely, in those of the white substance (inflammatory in nature). These aspects are confirmed in MRI. There is no strict correlation between radiological and clinical signs or symptoms. Most CT scan or MRI brain abnormalities disappear in four to eight weeks post-infection as well as the clinical signs and symptoms (DupouyCamet and Bruschi, 2007). Usually, the CSF is normal, however sometimes protein content and lymphocyte and eosinophil levels are moderately increased. Moreover, it is also possible to detect Trichinella larvaein CSF (Neghina et al, 2011).

Taenia solium: Neurocysticercosis (NCC) is a common neurological disorder caused by the encysted larva of the tapeworm Taenia solium. It develops after the ingestion of eggs from the faeces of a tapeworm carrier (i.e., fecal-oral contamination). Cysticercosis is highly endemic in most developing countries as a result of poor socioeconomic development and domestic pig raising (Kimura-Hayama et al, 2010).Diagnosis of this disease is based on a combination of param- eters which are not always pathognomonic. They included that the epidemiological information, clinical as well as serological data (which should be confirmed with an immunoblotting), and also brain imaging with either CT or MRI. Sometimes, it is possible to carry out direct diagnosis by means of histopathology. Diagnostic criteria for the neuro-cysticercosis have been proposed (Del Brutto et al, 2001), but not yet validated in a systematic way (Nash and Garcia, 2011). Imaging of the CNS is very useful not only to make the diagnosis but also to visualize the localization and types of cysticerci. If MRI is more useful for visualizing the brain structures and anatomy as well as cysts, CT can better detect the calcifications. For these reasons, both techniques should preferentially be used to help the clinician in the treatment of choice (Garcia and Del Brutto, 2003). Neuroimaging of parenchymal NCC depends on the stage of the development of the parasites (Lerner et al, 2012). CNS imaging results can identify a NCC case when they visualize one or more cysts with a round shape of $1-2 \mathrm{~cm}$ in diameter, with smooth walls with a "hole with dot" appearance that represents the scolex(Garcia et al, 2005). When multiple similar lesions or multiple lesions of a range of types compatible with neurocysticercosis are present, the diagnosis is more easily confirmed (Nash and Garcia, 2011).

In the vesicular stage, viable cysts are clearly visible, even with $\mathrm{CT}$, but when they begin to degenerate they can be visualised only by means of MRI, after contrast medium administration, which shows an enhancement most probably caused by inflammation around a cyst that is still viable (Garcia and Del Brutto, 2003). This is the colloidal stage of the cyst, representing the so-called "acute encephalitic phase" of NCC (Coyle and Tanowitz, 2009). When the cysts degenerate further they become opaque, and at the MRI they are accompanied by marked enhancement(Dumas et al, 1997).In patients with a single lesion surrounded by en- 
hancement, the diagnosis of NCC is difficult for two reasons: i) the morphology of the cysts is not characteristic; ii) serological tests are often negative, probably because of antigen seclusion(Nash and Garcia, 2011). The final stage is represented by calcification of the cysts which appear typically as small, punctate and round, hyperdense nodules without perilesional edema but exceptions are possible. If single calcification is present it is more probable that the patient originates from endemic countries, but in that case diagnosis of NCC can be made only in the presence of other clinical findings (Nash et al, 1934).

Subarachnoid-cisternal neurocysticercosis involves the subarachnoid spaces and adjacent meninges. This variety manifests as space-occupying lesions that may cause hydrocephalus, although this condition may also be secondary to basilar arachnoiditis. Moreover, adjacent brain edema with gliosis and vasculitis may occur. The cysticerci manifest the same pathological evolution and radiological features as in case of parenchymal cysts (Kimura-Hayama et al, 2010).

Ventricular neurocysticercosis is reportedly responsible for anywhere from $0.7 \%$ to $33 \%$ of all cases of neurocysticercosis (Sotelo et al, 1985; Cuetter et al, 1997), with the fourth ventricle being the most common site $(50 \%)$, followed by the lateral ventricles $(35 \%)$, third ventricle $(10 \%)$, and aqueduct (5\%) (Villagran-Uribe and Olvera-Rabiela, 1988).It often leads to obstructive hydrocephalus and ventriculitis due to ependymal inflammation (i.e., granular ependymitis and subependymal gliosis) or adhesions due to previous ventricular involvement (Noujaim et al, 1999). Intraventricular cysticerci appear at CT as cystic lesions that are initially iso-attenuating relative to CSF and thus not well visualized. Their presence could therefore be suspected from distortions of the ventricular system causing asymmetric or obstructive hydrocephalus that appears as disproportionate ventricular dilatation. On the other hand, most intraventricular cysts are well defined at MR imaging because their signal intensity may differ slightly from that of CSF on T1- or T2-weighted images (Kimura-Hayama et al, 2010).

Finally, in patients with spinal NCC, CT may be useful in showing intramedullary cysts which are responsible for a symmetrical enlargement of the cord, or leptomeningeal cysts (when the formations are within the spinal canal)(Coyle and Tanowitz, 2009).By MRI, intramedullary cysticerci appear as ring enhancing lesions with possibly an eccentric hyperintense nodule corresponding to the scolex(Garcíaet al, 2003).

Cystic echinococcosis (hydatid disease): Hydatid disease is endemic in several parts of the world especially the Middle East, Australia, New-Zealand, South and Central America, and Southern Europe (McCullagh, 1996). Infection is acquired by ingestion of eggs of dog Taenia worm Echinococcus granulosus. In series from several parts of the world, brain hydatid cysts make up approximately $1-3 \%$ of cases of cystic echinococcosis (Gezen et al, 1995).

The hydatid cyst occurs singly in the brain as a space-occupying mass lesion, usually located in the white matter in the territory of middle cerebral artery. It gives rise early to manifestations of increased intracranial tension such as headache, nausea, vomiting and papilloedema. Unlike cysticercosis, seizures are uncommon. The affected individuals are mostly children and young adults. In $20 \%$ of cases hepatic cysts are also found(Hughes and Biggs, 2002; Paugam, 2008).Spinal cord hydatid disease occurs in less than $1 \%$ of cases, and it may be intra- or extramedullary. Of these, $10 \%$ occur in the cervical, $50 \%$ in the thoracic and $20 \%$ in the lumbar and sacral spine, respectively (Tuzun and Hekimoglou, 1998). Cysts usually affect the vertebral bodies with secondary involvement of the cord. Echinococcosis affects the vertebral bodies after haematogenous spread from the portal circulation. The usual trilaminar cyst wall is not observed 
when cysts develop in bone and they do not have the typical well-defined appearance. Instead, they tend to expand irregularly along pathways of least resistance and may erode through the bony cortex into the spinal canal. The principal differential diagnosis in these cases is tuberculous spondylitis. Spinal canal hydatid cysts are commonly multiple and tend to recur after surgery. Clinical manifestations include paresis, radicular features, and cauda equina syndrome(Altinors et al, 2000).

The diagnosis relies on imaging techniques along with serological tests. Serology is relatively insensitive for brain hydatids, possibly due to the privileged immunological nature of the brain. However, histopathological examination of surgical specimens is definitive. At CT, there is often a large solitary spherical cyst, with a regular smooth border and a cyst-content of fluid density similar to CSF. Calcification may be seen on non-contrast CT, even if it is minimal. There is usually no rim enhancement or perifocal edema. Daughter cysts may be produced re- sulting in internal septations. MRI is slightly more sensitive than CT(Bukte et al, 2004; Polat et al, 2003).

\section{Conclusion}

The diagnostic efforts of CNS diseases of parasitic origin entail the collaboration of the neurologist, neurosurgeon, radiologist, and, last but not least, the clinical parasitologist. Figure (1) summarizes the different diagnostic steps, and Table (1) summarizes the major CNS parasitic helminth infections. The parasitic infections should be readily evoked in tropical zones before a relevant history and clinical features, and especially in the presence of characteristic biological parameters e.g. blood or CSF eosinophilia. Other non-parasitic infections are also common in the tropics and should be taken into consideration. In temperate zones, however, parasitic CNS diseases could be evoked before history of travel to endemic areas or unusual food, or in the context of immunosuppression.

Table 1: Major CNS helminthic infections: clinical and diagnostic features

\begin{tabular}{|c|c|c|}
\hline Parasite & Patho-clinical features & Diagnostic procedures \\
\hline $\begin{array}{l}\text { Schistosoma spp. } \\
\text { S. japonicum } \\
\text { S. mansoni/haematobium }\end{array}$ & $\begin{array}{l}\text { Cerebral granulomas: seizures } \\
\text { Myelopathy: paralysis, radicular fea- } \\
\text { tures, cauda equina syndrome }\end{array}$ & $\begin{array}{l}\text { Demonstration of schistosomal infection } \\
\text { by microscopy, serological methods, his- } \\
\text { topathology, and imaging features, and } \\
\text { favourableresponse to therapy }\end{array}$ \\
\hline $\begin{array}{l}\text { Paragonimus } \text { spp.(Hughes } \\
\text { and Biggs, 2002, Andri- } \\
\text { amanantena et } a l, 2005)\end{array}$ & $\begin{array}{l}\text { Space-occupying lesions, seizures, } \\
\text { hemiplegia, visual impairement, eo- } \\
\text { sinophilic meningitis }\end{array}$ & $\begin{array}{l}\text { Sputum examination, serology, imaging, } \\
\text { histopathology }\end{array}$ \\
\hline Neurocysticercosis & $\begin{array}{l}\text { Epilepsy, intracranial hypertension, } \\
\text { hydrocephalus, meningitis }\end{array}$ & $\begin{array}{l}\text { Serology, antigen or antibody in CSF, } \\
\text { imaging (CT and MRI), histopathology }\end{array}$ \\
\hline Cystic echinococcosis & Mass lesion in brain or spinal cord & Serology, CT \& MRI,\& histopathology \\
\hline Strongyloides stercoralis & $\begin{array}{l}\text { Purulent or aseptic meningitis, cere- } \\
\text { bral microinfarcts and abscesses. }\end{array}$ & $\begin{array}{l}\text { Stool, sputum, and CSF examination, } \\
\text { serology, and CSF bacterial cultures }\end{array}$ \\
\hline Toxo & $\begin{array}{l}\text { Eosinophilic meningitis, meningoradi- } \\
\text { culitis, behavioural and sleep prob- } \\
\text { lems, epilepsy (?) }\end{array}$ & Serology \\
\hline Trichinella spp. & Meningitis, encephalitis & $\begin{array}{l}\text { ts, muscle biopsy, periph- } \\
\text { ia }\end{array}$ \\
\hline $\begin{array}{l}\text { Angiostrongylus cantonen- } \\
\text { sis(Bouréeet al, 2010, Graeff- } \\
\text { Teixeira et al, 2009) }\end{array}$ & $\begin{array}{l}\text { Eosinophilic meningitis, cranial nerve } \\
\text { lesions, radiculopathy }\end{array}$ & History, CSF eosinophilia, serology \\
\hline $\begin{array}{l}\text { Gnathostoma spinig- } \\
\text { erum(Hug-hes and Biggs, } \\
\text { 2002; Graeff-Teixeira et al, } \\
\text { 2009) }\end{array}$ & $\begin{array}{l}\text { Multiple cranial nerve lesions, radicu- } \\
\text { li-tis, transverse myelitis, subarach- } \\
\text { noid haemorrhage, eosinophilic men- } \\
\text { ingitis }\end{array}$ & $\begin{array}{l}\text { CSF examination, serology, histopatholo- } \\
\text { gy }\end{array}$ \\
\hline
\end{tabular}




\section{Remarks}

The authors have no conflicts of interest.No funding sources to be declared for this review article, and Dr. Ahmad A. Othman, Prof. Dr. Fabrizio Bruschi, and Dr. Ahmed A. Ganna report no disclosures.

Search strategy and selection criteria: We searched PubMed from Jan 1, 2000, until Feb 28, 2012, with the terms parasites and CNS, CSF and parasites, neuroschistosomiasis, neurocysticercosis, neurotoxocariasis, neurotrichinosis, and Strongyloides stercoralis hyperinfection. Important review articles and relevant chapters in authoritative textbooks on the subject were also identified through searches of authors' personal libraries, andreviewed papers written in both English and French.

\section{References}

Almedia CR, Ojopi EP, Nunes CM.et al, 2006:Taenia solium DNA is present in cerebrospinal fluid of neurocysticercocis patients and can be used for diagnosis. Eur. Arch. Psychiatry Clin. Neurosci. 256: 307-10.

Altinors, N, Bavbek, M, Caner, HH, Erdogan, B, 2000: Central nervous system hydatidosis in Turkey: a cooperative study and literature survey analysis of 458 cases. J. Neurosurg. 93:1-8.

Andriamanantena D, Rey, P, Perret, JL, Klotz, F, 2005: Distomatoses.EMC-Mala-dies Infectieuses. 2:105-18.

Arpino, C, Gattinara, GC, Piergil, D, Curatolo, P, 1990: Toxocara infection and epilepsy in children: a case-control study. Epilepsia 31:33-6.

Atadzhanov, M, 2009: Tropical neurology, in: Cook, G.C., Zumla, A.I. (Eds.), Manson's Tropical Diseases. $22^{\text {nd }}$ edition. Saunders Elsevier.

Azuma, K, Yashiro, N, Kinoshita, T, Yoshigi, J, Ihara, N, 2002: Hepatic involvement of visceral larva migrans due to Toxocara canis: a case report- CT and MR findings. Radiat. Med.20:89-92.

Badr, HI, Shaker, AA, Mansour, MA, Kasem, MA, Zaher, AA, et al, 2011: Schistosomal myeloradiculopathy due to Schistosoma mansoni: Report on 17 cases from an endemic area. Ann. Indian. Acad. Neurol. 14:107-10.
Bourée, P, Dumazedier, D, Dahane, N, 2010: Angiostrongyloïdoseou méningite à éosinophiles. La revue du praticien. 60:456-8.

Bukte, Y, Kemaloglu, S, Nazaroglu, H, Ozkan, U, Ceviz, A, et al, 2004:Cerebral hydatid disease: CT and MRI imaging findings. Swiss Med. Wkly. 134:456-67.

Celedon, JC, Mathur-Wagh, U, Fox, J, Garcia, R, Wiest, PM, 1994: Systemic strongyloidiasis in patients infected with the human immunodeficiency virus. A report of 3 cases and review of the literature. Medicine (Baltimore) 73:256-63.

Chitsulo, L, Engels, D, Montresor, A, Savioli, L, 2000: The global status of schistosomiasis and its control. Acta Trop.77:41-51.

Cox, DM, Holland, CV, 2001: Relationship between three intensity levels of Toxocara canis larvae in the brain and effects on exploration, anxiety, learning and memory in the murine host. J. Helminthol.75:33-41.

Coyle, CM, Tanowitz, HB, 2009: Diagnosis and treatment of neurocysticercosis. Interdiscip. Perspect. Infect. Dis.: 180742. doi: 10.1155/2009 /180742.

Cuetter, AC, Garcia-Bobadilla, J, Guerra, LG, Martinez, FM, Kaim, B, 1997: Neurocysticercosis: focus on intraventricular disease. Clin. Infect. Dis. 24, 2:157-64.

De Graef, M, Smadja, P, Benis, J, Turpin, F, Liouane, M, et al, 2000: Neurotrichinosis: a case report with MRI evaluation. J. Radiol. (Paris) $81: 817-9$.

Del Brutto, OH, Rajshekhar, V, White, ACJr, Tsang, VC, Nash, TE, et al, 2001: Proposed diagnostic criteria for neurocysticercosis. Neurology 57:177-83.

Diagana, M, Millogo, A, Bouteille, B, Preux, PM, 2005: Neurological diseases in tropical countries. EMC-Neurol.2:232-59.

Dorny, P, Praet, N, Deckers, N, Gabriel, S, 2009: Emergingfood-borneparasites.

Vet. Parasitol. 163:196-206.

Dumas, JL, Visy, JM, Belin, C, Gaston, A, Goldlust, D, et al, 1997: Parenchymal neurocysticercosis: follow up and staging by MRI. Neuroradiology 3:12-8.

Dupouy-Camet, J, Bruschi, F, 2007: Management and diagnosis of human trichinellosis. In: $\mathrm{FAO}=\mathrm{WHO}=\mathrm{OIE}$ Guidelines for the Surveil- 
lance, Management, Prevention and Control of Trichinellosis. Dupouy-Camet J and Murrell KD (eds.). Paris: $\mathrm{FAO}=\mathrm{WHO}=\mathrm{OIE}$.

Durack, DT, Sumi, SM, Klebanoff, SJ, 1979: Neurotoxicity of human eosinophils. Proc. Natl Acad. Sci. USA76:1443-7.

Ellrodt A, Halfon P, Le Bras P, Halimi P, Bourée P, Dési M, Caquet R., 1987: Multifocal central nervous system lesions in three patients with trichinosis. Arch Neurol44: 432-4.

Ferrari, TC, Gazzinelli, G, Correa-Olive-ira, R, 2008: Immune response and pathogenesis of neuroschistosomiasis mansoni. Acta Trop.108: 83-8.

Ferrari, TC, Moreira, PR, 2011: Neuroschistosomiasis: clinical symptoms and pathogenesis. Lancet Neurol.10: 853-64.

Feydy, A, Touze, E, Miaux, Y, Bolgert, F, Martin-Duverneil, et al, 1996: MRI in a case of neurotrichinosis. Neuroradiology38: S80-2.

Finsterer, J, Auer, H, 2007: Neurotoxocarosis. Rev. Inst. Med. Trop. Sao Paulo 49: 279-87.

Forsgren, L, Beghi, E, Oun, A, Sillanpaa, M, 2005: The epidemiology of epilepsy in Europe-a systematic review. Eur. J. Neurol. 12:245-53.

Fourestié, V, Douceron, H, Brugieres, P, Ancelle, T, Lejonc, JL, et al, 1993: Neurotrichinosis. A cerebrovascular disease associated with myocardial injury and hypereosinophilia.Brain 116:603-16.

Garcia, HH, Del Brutto, OH, Nash, TE, White, AC-Jr, Tsang, VC, et al, 2005: Newconcepts in the diagnosis and management of neurocysticercosis (Taeniasolium).Am. J. Trop. Med. Hyg. 72:3-9.

Garcia, HH, Del Brutto, OH, 2003: Imaging findings in neurocysticercosis. Acta Trop.87:718.

Garcia, LS, 2007: Diagnostic medical parasitology. $5^{\text {th }}$ edition. ASM Press. Washington DC, USA.

Gelal, F, Kumral, E, Vidinli, BD, Erdo- gan D, Yucel, K, et al, 2005: Diffusion-weighted and conventional MR imaging in neurotrichinosis. Acta Radiol.46:196-9.

Gezen, F, Baysefer, A, Koksel, T, Gonul, E, Akay, KM, et al, 1995: Hydatid cysts of the brain. Clin. Infect. Dis.21:938-42.

Goffette, S, Jeanjean, AP, Bigaignon, G, Sindi, CJ, 2000: Eosinophilic pleocytosis and mye- litis related to Toxocara canis infection. Eur. J. Neurol.67: 703-6.

Graeff-Teixeira, C, da Silva, AC, Yoshimura, K, 2009: Update on eosinophilic meningoencephalitis and its clinical relevance. Clin. Microbiol. Rev.22:322-48.

García, HH, Armando E, Gonzalez, Carlton A W, Evans, Robert H, Gilman, RH; Cysticercosis Working Group in Peru, 2003: Taenia solium cysticercosis. The Lancet 362:54756.

Hénon, H, Vermersch, P, Dutoit, E, Dubois, F, Camus, D, et al, 1995: Myélite à anguillule. Rev. Neurol.151:139-41.

Holland, CV, Cox, DM, 2001:Toxocara in the mouse: a model for parasite-altered host behaviour? J. Helminthol.75:125-35.

Hughes, AJ, Biggs, BA, 2002: Parasitic worms of the central nervous system: an Australian perspective. Int. Med. J. 32:541-53.

Jaroonvesama, N, 1988: Differential diagnosis of eosinophilic meningitis. Parasitol. Today 4:262-6.

Jauréguiberry, S, Paris, L, Caumes, E, 2010: Acute schistosomiasis, a diagnostic and therapeutic challenge. Clin. Microbiol. Infect. 16:225-31.

John, DT, Petri, WA, 2006: Signs and Symptoms of Parasitic Diseases.In: Markell and Voge's Medical Parasitology. th $^{\text {th }}$ edition. Saunders Elsevier.

Katchanov, J, Nawa,Y, 2010: Helminthic invasion of the central nervous system: Many roads lead to Rome. Parasitol. Int. 59: 491-6.

Keiser, PB, Nutman, TB, 2004: Strongylo- ides stercoralis in the immunocompromised population. Clin. Microbiol. Rev.17:208-17.

Kimura-Hayama, ET, Higuera, JA, CoronaCedillo, R, Chávez-Macías, L, Pero-chena, A, et al, 2010: Neurocysticercosis: radiologicpathologic correlation. Radiogra- phics 30:170519.

Kramer, MR, Gregg, PA, Goldstein, M, Llamas, R, Krieger, BP, 1990: Disseminated strongyloidiasis in AIDS and non-AIDS immunocompromised hosts: diagnosis by sputum and bronchoalveolar lavage. South Med. J. 83:12269.

Kuberski T, 1979: Eosinophils in the cerebrospinal fluid. Ann. Int. Med.91:70-5. 
Lambertucci, JR, dos Santos Silva, LC, Andrade, LM, de Queiroz, LC, Carvalho, VT, et al, 2008: Imaging techniques in the evaluation of morbidity in schistosomiasis mansoni. Acta Trop. 108:209-17.

Lerner, A, Shiroishi, MS, Zee, CS, Law, M, Go, JL, 2012:Imaging of neurocysticercosis. Neuroimaging. Clin. N. Am. 22:659-676.

Liepman, M, 1975: Disseminated Strongyloides stercoralis. A complication of immunosuppression. JAMA 231:387-8.

Link, K, Orenstein, R, 1999: Bacterial complications of strongyloidiasis: Streptococcus bovis meningitis. South Med. J.92:728 -31.

Magnaval, JF, Dorchies, P, Glickman, L T, 2005: Toxocara species (Toxocariasis). In: Yu, V.L. et al. (Eds.), Antimicrobial the-rapy and vaccines, Vol. I. $2^{\text {nd }}$ edition. ESun Technologies LLC, Pittsburgh, PA, USA.

Magnaval, JF, Glickman, LT, Dorchies, P, Morassin, B, 2001: Highlights of human toxocariasis. Korean J. Parasitol. 39:1-11.

Mawhorter, ST, Kazura, JW, 1993: Trichinosis of the central nervous system. Semin. Neurol. 13:148.

McCullagh, PJ, 1996: Hydatid disease: medical problems, veterinary solutions, political obstacles (editorial; comment). Med. J. Aust. 164:7-8.

Nash, TE, Garcia, HH, 2011: Diagnosis and treatment of neurocysticercosis Nat. Rev. Neurol.13:584-94.

Nash, TE,et al., 2004:Calcific neurocysticercosis and epileptogenesis. Neurology 62: 1934-8.

Neghina, R, Neghina, AM, Marincu, I, Iacobiciu I., 2011: Reviews on Trichinellosis (II): Neurological Involvement. Foodborne Pathog. Dis. 8:579-85.

Nicolas, X, Chevalier, B, Klotz, F, 2005: Anguillule et anguillulose (Strongyloides and stongyloidiasis). EMC-Maladies Infecti- euses2:4258.

Noujaim, SE, Rossi, MD, Rao, SK, et al, 1999: $\mathrm{CT}$ and MR imaging of neurocysticercosis. AJR Am. J. Roentgenol. 173, 6: 1485-90.

Paugam, A, 2008: Parasitoses et atteinte neurologique. Revue Francophone des Laboratoires399:41-53.

Peyron, F, Barret, L, Siche, JR, Goullier, A, Debru, JL, 1985: Manifestation neuro- logique inhabituelle de l'anguillulose. Presse Méd.14: 490-7.

Polat, P, Kantarci, M, Alper, F, Suma, S, Koruyucu, MB, et al, 2003: Hydatid disease from head to toe. Radiographics 23: 475-94.

Preux, PM, Diagana, M, Nsenguymva, G, Druet-Cabanac, M, 2002: Epilepsie enzo- ne tropical. Neurologies 5:216-20.

Reeder, MM, Palmer, FE, 2001: Toxoplasmosis. In: The Radiology of Tropical Diseases with Epidemoliogical, Pathological, and Clinical Correlation. Williams \& Wilkins, Baltimore. Online version available at $<<$ http://www. isradiology.org/tropical_diseases/tmcr/chapter45/ imaging $>>$.

Robinson, A, Tannier, C, Magnaval, JF, 2002: Toxocara canis meningoradiculitis. Rev. Neurol. (Paris) 158:351-3.

Ryczak, M, Sorber, WA, Kandora, TF, Camp, CJ, Rose, FB, 1987: Difficulties in diagnosing Trichinella encephalitis. Am. J. trop. Med. Hyg.36:573-5.

Scowden, EB, Schaffner, W, Stone, WJ, 1978: Overwhelming strongyloidiasis: an unappreciated opportunistic infection. Medicine (Baltimore)57:527-44.

Scrimgeour, EM, Gajdusek, DC，1985: Involvement of the central nervous system in Schistosoma mansoni and S. haematobium infection: a review. Brain108:1023-38.

Silva, LCS, Maciel, PE, Ribas, JG, SouzaPereira, SR, Antunes, CM, et al, 2004: Treatment of schistosomal myeloradiculopathy with praziquantel and corticosteroids and evalua-tion by magnetic resonance imaging: a longitudinal study. Clin. Infect. Dis.39:1619-24.

Solomon, T, Danesi, M, Bia, FJ, Bleck, TP, 2006: Neurologic Disease, in: Guerrant, RL, Walker, DH, Weller, PF (Eds.), Tropical Infectious Disease: Principles, Pathoge- ns, \& Practice. 2nd edition. Elsevier/ Chur-chill Livingston, Philadelphia.

Sotelo, J, Guerrero, V, Rubio, F, 1985: Neurocysticercosis: a new classification based on active and inactive forms- a study of 753 cases. Arch. Int. Med.145:442-5.

Steinmann, P, Keiser, J, Bos, R, Tanner, M, Utzinger, J, 2006: Schistosomiasis and water resources development: systematic review, meta-analysis, and estimates of people at risk. Lancet. Infect. Dis. 6:411-25. 
Taylor, MR, Keane, CT, O`Connor, P, Mulvihill, E, Holland, C, 1988: The expanded spectrum of toxocaral disease. Lancet 1:692-5.

Tuzun, M, Hekimoglu, B, 1998: Hydatid disease of the CNS: imaging features. Am. J. Roentgenol. 171:1497-500.

Vadlamudi, RJ, Chi, DS, Krishnaswamy, G, 2006: Intestinal strongyloidiasis and hyperinfection syndrome. Clin. Mol. Allergy 30:4-8.

Vidal, JE, Sztajnbok, J, Seguro, AC, 2003:

Eosinophilic meningoencephalitis due to Toxocara canis. Case report and review of literature. Am. J. Trop. Med. Hyg. 69: 341-3.

Villagran-Uribe, J, Olvera-Rabiela, JE, 1988:

Cisticercosis humana: estudio clínico y patológico de 481 casos de autopsia. Patologia 26:14956.
Vishwanat, S, Baker, RA, Mansheim, BJ, 1982: Strongyloides infection and meningitis in an immunocompromised host. Am. J. Trop. Med. Hyg.31:857-58.

Wilson, ME, Weller, PF, 2006: Eosinophilia, in: Guerrant, RL, Walker, DH, Weller, P F (Eds.), Tropical Infectious Disease: Principles, Pathogens, \& Practice. $2^{\text {nd }}$ edition. Elsevier/Churchill Livingston, Philadelphia.

Worely, G, Green, JA, Frothingham, TE, 1984: Toxocara canis infection. Clinical and epidemiological association with seropositivity in Kindergarten children. J. Infect. Dis. 149: 591-7.

Xinou, E, Lefkopoulos, A, Gelagoti, M, Drevelegas, A, Diakou, A, et al, 2003: CT and MR imaging findings in cerebral toxocaral disease. AJNR Am. J. Neuroradiol. 24: 714-8. 


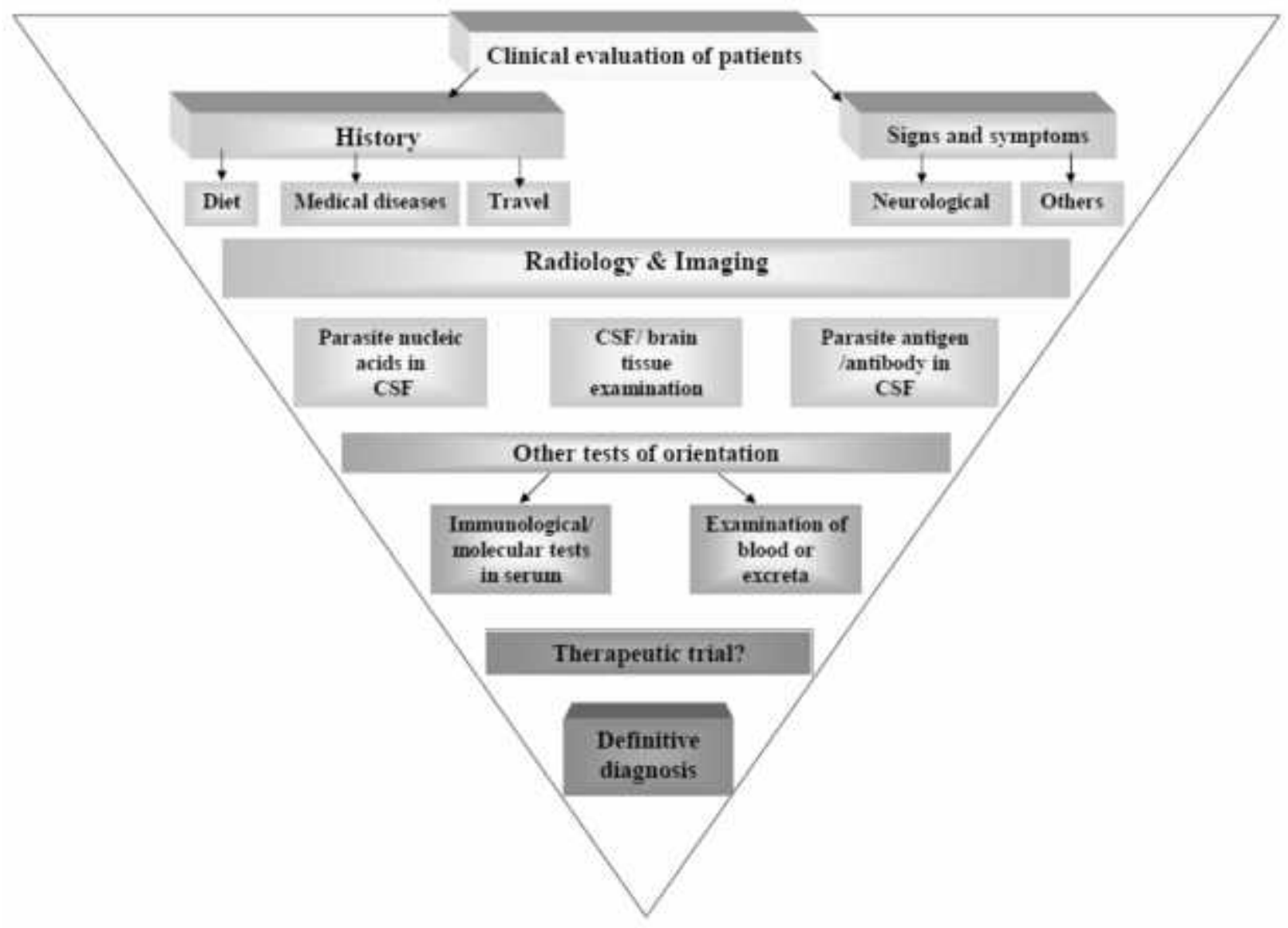

Figure 1: Stepwise diagnostic approach to parasitic CNS infections. At any level the diagnosis may be established. 